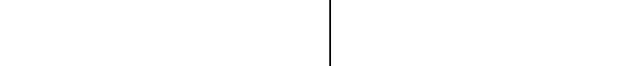

Rev. Latinoam. Psicopat. Fund., São Paulo, v. 11, n. 4, p. 762-778, dezembro 2008 (Suplemento)

\title{
Da enfermidade chamada banzo: excertos de Sigaud e de von Martius (1844)*
}

Ana Maria Galdini Raimundo Oda

Este artigo discute dois relevantes estudos sobre as doenças no Brasil do século XIX, escritos por Joseph François Xavier Sigaud e por Carl Friedrich Philipp von Martius. Ambos tratam da nostalgia dos escravos, a enfermidade chamada de banzo.

Palavras-chave: Escravidão, psicopatologia, Joseph François

Xavier Sigaud, Carl Friedrich Philipp von Martius

* Financiamento: Fundação de Amparo à Pesquisa do Estado de São Paulo - Fapesp (processo 04/00442-4). 
Este artigo comenta dois importantes estudos sobre as doenças no Brasil da primeira metade do século XIX, dos quais transcreverei os excertos que tratam da enfermidade chamada de banzo: o do médico francês Joseph François Xavier Sigaud (1796-1856) e o do naturalista (e médico) bávaro Carl Friedrich Philipp von Martius (1794-1868). ${ }^{1}$

\section{Sigaud e sua viagem pelo Brasil}

O tratado Du climat et des maladies du Brésil (Do clima e das doenças do Brasil) foi publicado em Paris, em 1844. José Francisco foi o prenome adotado pelo francês naturalizado brasileiro, formado em Estrasburgo em 1818, e que chegou em 1825 ao país onde viveria por trinta anos. Foi médico do jovem imperador Pedro II, pioneiro da imprensa nacional, editor de periódicos médicos, fundador e presidente da Sociedade de Medicina do Rio de Janeiro, membro do Instituto Histórico e Geográfico Brasileiro, e atuante filantropo (Sacramento-Blake, 1898). Para Ferreira (1998), na Sociedade de Medicina, José Francisco Sigaud uniu "a atividade de editor científico com a de investigador interessado em explicar a situação sanitária brasileira” (p. 125), considerando-a em sua imensa diversidade e complexidade, sendo o livro Du climat... resultado deste ambicioso projeto de pesquisa. ${ }^{2}$

1. Veja-se também meu artigo Escravidão e nostalgia no Brasil: o banzo, neste suplemento.

2. É notável que esta relevante obra de referência para a história das ciências não tenha sido, até o presente momento, editada em português. Parte da quarta seção do livro, que se ocupa da biografia dos médicos, cirurgiões e naturalistas do Brasil, foi transcrita em artigo de Sérgio Góes de Paula (1998). A Editora da Fiocruz planeja em breve publicar a primeira tradução do tratado de Sigaud. 
A obra é extensa e o autor anota cuidadosamente suas variadas fontes, obtidas no Brasil e na França, incluindo trabalhos sobre a história brasileira, obras médicas nacionais e estrangeiras, em especial aquelas sobre as moléstias tropicais e as doenças dos escravos (Dazille, Levacher, Lind, Rush, Pinto de Azeredo etc.), e muitos relatos de cronistas, viajantes e naturalistas. Entre estes, estão Marcgrave, A. de Saint-Hilaire, Spix e Martius, Koster, Lindley, D’Orbigny, La Condamine e Humboldt, modelo cuja inspiração o médico francês evoca na introdução de seu livro. Pode-se dizer que Sigaud é um viajante científico: ainda que não tenha se deslocado geograficamente pelo Brasil, certamente empreendeu uma longa jornada através de três séculos de documentação, escrita em latim, português, espanhol, francês, inglês e italiano, conforme menciona o autor em suas páginas iniciais.

A epígrafe do livro, de autoria de Cabanis, indica o seu princípio norteador: "Cada latitude tem sua marca, cada clima tem sua cor" (Chaque latitude a son empreinte, chaque climat a sa couleur). A partir da perspectiva da climatologia médica ou neo-hipocratismo, ${ }^{3}$ o autor discute a relação entre climas, ambientes (ares, águas e lugares) e patologias, tratando das peculiaridades da terra, das características e dos hábitos da população do Brasil, sempre de forma comparativa, com relação à Europa, à África, às Antilhas e às Américas. Neste ponto, não é irrelevante considerar que ao autor parece interessar a veiculação de uma certa imagem positiva de sua pátria adotiva, a cujo imperador, Pedro II, é dedicado o tratado.

Coerentemente com sua proposta de relacionar patologia, ambiente natural e modus vivendi, o tratado está dividido em quatro seções: climatologia (variações térmicas e barométricas, umidade e chuvas, ventos etc.); geografia médica (alimentação e aclimatação, doenças dos índios e dos negros, curandeiros, doenças endêmicas e epidêmicas); patologia intertropical (febres intermitentes, tísica, doenças nervosas, picadas de insetos, mordeduras de serpentes etc.); e estatística médica do Brasil (composição racial da população, taxas de mortalidade, legislação sanitária etc.).

No decorrer do tratado, várias vezes Sigaud assinala que a incidência e as manifestações das doenças não diferem substancialmente entre as raças branca, negra ou índia, ou entre negros e brancos europeus, importando mais os fatores climáticos, ambientais e as condições de vida (alimentação, exposição ao frio, à

3. Para uma sintética revisão sobre a climatologia médica, e sobre suas aplicações ao Brasil, vejase artigo de Flávio Edler (2001). 
umidade, ao calor, excesso de trabalho, abuso de álcool, verminoses etc.) de cada grupo, ainda que indique que algumas enfermidades pareçam ser "atributos da raça negra”. No capítulo dedicado às moléstias dos negros escravos, menciona certas doenças que relaciona ao tráfico transatlântico, como o escorbuto e a disenteria, e descreve doenças consideradas comuns entre eles, como a caquexia africana (que liga à ingestão de terra), o maculo (gangrena retal), a sífilis, a tísica, a oftalmia que poderia levar à amaurose (cegueira) etc.

$\mathrm{Na}$ seção em que trata do que chama de doenças nervosas, começa discordando de um princípio adotado por muitos de seus colegas europeus, o de que os negros seriam pouco propensos às enfermidades mentais, com exceção da idiotia. Aqui, ao afirmar que a loucura furiosa, ou mania, existia entre os negros, e ainda quando fala dos suicídios de escravos, ele discute com a literatura médica contrastando-a com sua experiência clínica nos trópicos. Sua experiência pessoal é, também, invocada para defender um curioso (e muitíssimo improvável) método de suicídio dos africanos escravos, a sufocação (etouffement), que consistiria em sufocar-se engolindo a própria língua. Ao falar do banzo, Sigaud cita o ensaio de Luis Antonio de Oliveira Mendes (de 1793), ${ }^{4}$ apoiando-se em sua descrição daquelas "mortes lentas, espécies de consumpções produzidas pela inanição, e devidas a uma causa moral”, tais como a nostalgia da terra natal ou o ressentimento causado por castigos injustos. Cumpre observar que a memória de Oliveira Mendes é uma importante fonte de Sigaud para a descrição das doenças dos negros; é com um elogio ao citado trabalho que ele abre o capítulo intitulado Doenças dos negros (Sigaud, 1844, p. 126 e seguintes, transcritas adiante).

Mais adiante, trata das doenças nervosas em geral (que são: epilepsia, coqueluche, asma, histeria, hipocondria e loucura), que pondera serem "afecções díspares, de sede indeterminada, mas nas quais o elemento nervoso constitui o verdadeiro caractere” (Sigaud, 1844, p. 353). Em especial com relação à histeria, à hipocondria e à loucura, Sigaud repete que não há diferenças na sua ocorrência segundo as raças, e que "os que pretenderam que índios e negros não eram suscetíveis à loucura, na verdade queriam separar estas duas raças das inevitáveis condições da humanidade” (p. 357).

4. Veja-se Oliveira Mendes, Luis Antonio de. Memória a respeito dos escravos e tráfico da escravatura entre a costa d’África e o Brasil (1812). Revista Latinoamericana de Psicopatologia Fundamental, v. 10, n. 2, p. 362-376, jul. 2007.

Rev. Latinoam. Psicopat. Fund., São Paulo, v. 11, n. 4, p. 762-778, dezembro 2008 (Suplemento) 


\section{Martius e os fleumáticos brasis}

O livro de Carl von Martius, Das Naturell, die Krankheiten, das Arztthum und die Heilmittel der Uberwohner Brasiliens (Natureza, doenças, medicina e remédios dos índios brasileiros) foi publicado em Munique em 1844; existe uma tradução brasileira, do médico parasitologista Manoel Augusto Pirajá da Silva, editada em 1939 e com segunda edição em 1979. ${ }^{5}$

O então jovem botânico Martius viajou pelo Brasil entre 1817 e 1820, na companhia do zoólogo J. B. von Spix (1780-1826), vindos ambos na expedição científica formada pelos governos da Áustria e da Baviera e incluída na comitiva da arquiduquesa Leopoldina, futura esposa do imperador Pedro I. O grupo chefiado por Spix e Martius fez uma longa viagem: desembarcou na cidade do Rio de Janeiro, seguiu em direção de São Paulo e de Minas Gerais, atravessou o sertão da Bahia, visitou a cidade de Salvador, penetrou por Pernambuco e Piauí até o Maranhão. Dali, subiu o rio Amazonas, chegou às fronteiras do Peru e da Colômbia, encerrando a viagem em Belém do Pará, de onde embarcou de volta a Munique (Macedo, 1938 [1869]).

O conjunto da obra do naturalista bávaro é vasto; a viagem ao Brasil forneceu-lhe material quase inesgotável para publicações, em especial na área de botânica e de etnografia, nos seus quase cinqüenta anos de vida depois da expedição. Alguns de seus estudos mais conhecidos são: Viagem pelo Brasil (1823-1831), com Spix; Genera et species palmarum (1823-1850); a monumental Flora brasiliensis (1840-1906, continuada após sua morte); e a monografia premiada pelo Instituto Histórico e Geográfico Brasileiro, intitulada Como se deve escrever a história do Brasil, de 1845 (Lisboa, 1997). Nesta última obra, escrita em português, se encontra a matriz da idéia sobre as contribuições de cada uma das três raças formadoras da nação, muitas vezes retomada pelos pensadores que se debruçaram sobre o processo de constituição da nossa nacionalidade.

De acordo com Karen Lisboa (1997), nos escritos de Martius é possível identificar o marcado influxo de Alexander von Humboldt, cuja obra serviu de modelo a muitos exploradores científicos, tanto na estruturação das viagens como

5. A edição mais recente é: Martius, Karl F. P. von. Natureza, doenças, medicina e remédios dos índios brasileiros (1844). Apresentação de Egon Schaden. Tradução, prefácio e notas de Pirajá da Silva. 2. ed. São Paulo: Companhia Editora Nacional, INL/MEC, 1979. (Brasiliana). Atualmente, este é um livro conhecido pelos historiadores das ciências mas que tem sido pouco explorado, com poucas exceções (Dalgalarrondo, 1999), e que certamente mereceria uma reedição comentada.

Rev. Latinoam. Psicopat. Fund., São Paulo, v. 11, n. 4, p. 762-778, dezembro 2008 (Suplemento) 
para a construção do tipo de narrativa que delas derivava. Além do modelo sistemático da história natural e das orientações de Humboldt, marcas do Romantismo alemão são claras nos trabalhos de Spix e Martius. ${ }^{6}$

Na introdução a Natureza, doenças, medicina..., Martius deixa claro que seu trabalho não se resume a um mero estudo etnográfico sobre povos exóticos, mas se reveste de séria importância para o futuro de um nascente império. Mescla de naturalista, etnógrafo e historiador (e, desta forma, autorizado profeta), ele pensa que a população autóctone faz parte de uma raça que desaparecerá; prevê que:

(...) os primitivos brasilíncolas [silvícolas brasileiros] serão lançados no grande redemoinho social e civil de onde, mais cedo ou mais tarde, surgirá uma população remodelada e nova - a do Império Brasileiro; que neste torvelinhar eles hão de perder, a mais e mais, suas características próprias e, finalmente, se extinguirão por completo (...) (Martius, 1939, p. 3 [1844])

O principal objetivo do livro é descrever as doenças observáveis (e, sobretudo, as diretamente observadas pelo autor) entre os indígenas brasileiros, os brasis, relacionando-as à sua constituição física e ao seu temperamento, e também apresentar os tratamentos ("medicina e remédios", principalmente os de origem vegetal) usados pelos silvícolas. Nesta tarefa, Martius lança mão de seus amplos conhecimentos como médico e naturalista e, principalmente, das informações recolhidas durante os três anos de sua viagem exploratória. Eventualmente, dialoga com outros trabalhos de referência, embora as notas bibliográficas não sejam freqüentes. Na introdução, posiciona sua própria produção científica, ao criticar a conhecida obra do cônego de Pauw sobre os naturais americanos (Indagações filosóficas acerca dos habitantes da América, 1769) por disseminar idéias fantasiosas, em razão de sua "propensão para o barroco e para o extraordinário"; desde logo, aponta seus autores preferidos, aqueles que prezavam a "observação sem preconceito”, tais como Alexander von Humboldt, Alcide D’Orbigny, Benjamin Rush e Samuel Morton (Martius, 1939, p. 2-3).

O médico-naturalista acredita que o temperamento dos índios é linfático, caracterizado pelo predomínio de humores frios (fleuma e bílis negra - ou melancolia), por fraca energia vital e por um sistema nervoso quase inerte, ainda que seu sistema muscular seja desenvolvido e tenha potente força física. Observa que,

6. Veja-se o trabalho de Karen M. Lisboa, A nova Atlântida de Spix e Martius, especialmente os capítulos II e III. Este livro é um excelente estudo sobre os conceitos de natureza e civilização na obra de Spix e Martius e sistematiza em estilo claro e elegante toda a intrincada discussão européia sobre o tema, nos séculos XVIII e XIX, e suas repercussões nas obras sobre o Brasil.

Rev. Latinoam. Psicopat. Fund., São Paulo, v. 11, n. 4, p. 762-778, dezembro 2008 (Suplemento) 
mesmo que habitem uma zona quente, os índios têm o sangue frio; eles são de natureza pesada e fria, "por assim dizer, quase anfíbios humanos" (Martius, 1939, p. 52). Praticamente, os brasis não teriam “vida psíquica superior” (idem, p. 34), sua vida mental é estreita e seus afetos são débeis; raramente coram de pejo (vergonha), mais vezes de raiva; são pusilânimes e facilmente se amedrontam. Eles, diz Martius, desconhecem "as paixões fortes e variadas, os sentimentos profundos e multiformes que determinam a vida e os atos dos europeus” (idem, p. 43); apenas o ódio e os ciúmes os transtornam, "porém, nos seus acessos, se assemelham mais às feras do que aos homens” (idem, p. 44); sofrem os maiores tormentos físicos com "estoicismo" (idem, p. 45) e desprezam a morte, sendo estes seus pontos de honra.

\section{Banzo de negro e banzo de índio}

Quando fala do banzo, Martius não menciona referências escritas, mas invoca o testemunho de colonizadores, fazendeiros e donos de escravos, e descreve o quadro como se o houvera visto, embora não o afirme textualmente.

Em todo o livro, as referências à natureza dos negros não são muitas, mas surgem sempre contrastando intensamente com aquela atribuída aos índios. Para Martius, se a marca do índio é a frieza e a falta - de afeto, de energia etc. -, a marca do negro é o excesso, o intenso calor físico e moral, a vivacidade de sentimentos. Estas características se expressariam, exemplarmente, nas diversas maneiras como, em cada raça, se manifesta o que chama de "o conhecido banzo”, mortal nostalgia decorrente da perda da liberdade: enquanto o índio se transforma em um autômato e permanece trabalhando, sombrio e definhando em silêncio, o negro não só sente muito mais como expressa seus sentimentos de forma aberta e dramática, acentuando-os ao máximo; fisicamente mais forte do que o índio, observa o naturalista, o negro resiste mais tempo neste espetacular estado melancólico.

A despeito de negar significativas diferenças na ocorrência das enfermidades segundo as raças, Sigaud aponta que entre os negros há uma evolução mais marcada das doenças nervosas, com manifestações mais intensas, o que exigiria uma terapêutica mais ativa, de acordo com sua constituição física e moral "mais forte”. Também para ele, o ardente caráter passional do negro tem no banzo a mais perfeita demonstração, quando nada pode vencer a sua resolução de se deixar morrer, nem ameaças de tormentos no presente, nem promessas de bem-estar no futuro. 
Dalgalarrondo, Paulo. Primeiros relatos sobre doenças mentais em nativos brasileiros: as descrições de Von Martius (1844). Revista Brasileira de Psiquiatria, v. 21, n. 1, p. 48-49, 1999.

EDLER, Flávio C. De olho no Brasil: a geografia médica e a viagem de Alphonse Rendu. História, Ciências, Saúde - Manguinhos, v. 8 (suplemento), p. 925-943, 2001.

Ferreira, Luiz Otávio. José Francisco Xavier Sigaud: um personagem esquecido, uma obra reveladora. História, Ciências, Saúde - Manguinhos, v. 5, n. 1, p. 125-126, 1998.

LisBoA, Karen Macknow. A nova Atlântida de Spix e Martius: natureza e civilização na Viagem pelo Brasil (1817-1820). São Paulo: Hucitec/Fapesp, 1997.

Macedo Joaquim Manuel de. Discurso na Sessão Magna Aniversária (15 de dezembro de 1869) do Instituto Histórico e Geográfico Brasileiro. In: SpIx, Johann Baptist von; MarTius, Carl Friedrich Philipp von. Viagem pelo Brasil. Rio de Janeiro: Imprensa Nacional. 1938. v. 1, p. xviii-xxiii.

Martius, Carl Friedrich Philipp von. Natureza, doenças, medicina e remédios dos índios brasileiros (1844). Tradução, prefácio e notas de Pirajá da Silva. São Paulo: Companhia Editora Nacional, 1939. [Tradução de Das Naturell, die Krankheiten, das Arztthum und die Heilmittel der Uberwohner Brasiliens].

Paula, Sérgio Goes de. Um inventário pioneiro de biografias para os historiadores das ciências. História, Ciências, Saúde - Manguinhos, v. 5, n. 1, p. 127-128, 1998.

Sacramento-Blake, Augusto Victorino Alves. Dicionário bibliográfico brasileiro. Rio de Janeiro: Imprensa Nacional. 1898. v. 4, p. 434-436.

Sigaud, Joseph François Xavier. Du climat et des maladies du Brésil ou statistique médicale de cette Empire. Paris: Fortin, Mason et C., 1844.

\section{Resumos}

(De la enfermedad llamada banzo: fragmentos de Sigaud y de von Martius [1844])

Este artículo discute dos estudios relevantes sobre la enfermedad en el Brasil del siglo XIX, escritos por Joseph François Xavier Sigaud y por Carl Friedrich Philipp von Martius. Ambos describen la nostalgia de los esclavos, la enfermedad llamada "banzo". Palabras clave: Esclavitud, psicopatología, Joseph François Xavier Sigaud, Carl Friedrich Philipp von Martius 
(De la maladie appelée banzo: extraits de Sigaud et de von Martius [1844])

Cet article discute deux importantes études sur les maladies au Brésil du XIXème siècle écrites par François Xavier Joseph Sigaud et par Carl Friedrich Philipp von Martius. Elles décrivent la nostalgie des esclaves, la maladie appelée "banzo".

Mots clés: Esclavage, psychopathologie, Joseph François Xavier Sigaud, Carl Friedrich Philipp von Martius

(The disease known as banzo: excerpts from Sigaud and von Martius [1844])

This article discusses two important studies on disease in $19^{\text {th }}$ century Brazil, written, respectively, by Joseph François Xavier Sigaud and Carl Friedrich Philipp von Martius. Both describe the slave nostalgia, the disease known as "banzo".

Key words: Slavery, psychopathology, Joseph François Xavier Sigaud, Carl Friedrich Philipp von Martius

\section{Ana Maria Galdini Raimundo Oda}

Psiquiatra; doutora em Ciências Médicas (Universidade Estadual de Campinas - Unicamp; Campinas, SP, Brasil); pesquisadora da Faculdade de Ciências Médicas da Unicamp; editora associada da Revista Latinoamericana de Psicopatologia Fundamental (seção História da Psiquiatria).

Caixa Postal 2135

13106-970 Campinas, SP, Brasil

e-mail: anaoda@uol.com.br

Rev. Latinoam. Psicopat. Fund., São Paulo, v. 11, n. 4, p. 762-778, dezembro 2008 (Suplemento) 
TRANSCRIÇÃo DE FONTES PRIMÁRIAS*

SigAud

Joseph François Xavier Sigaud. Du climat et des maladies du Brésil ou statistique médicale de cette Empire. Paris: Fortin, Mason et C., 1844.

Segunda seção. Geografia médica.

Capítulo III - Doenças dos negros (p. 126-129; p. 136-137 e p. 139-142). p. 126 , p. 127 e p. 128 :

Já há três séculos, milhões de negros têm vindo substituir a população, sempre decrescente, dos indígenas no Brasil, e sua introdução fez surgir uma série de doenças desconhecidas no país. Luis Antonio da Silva Mendes (sic) publicou nas Mémoires économiques de la Société royale de Lisbonne $e^{7}$ (sic), uma memória sobre as doenças agudas e crônicas dos negros recém-chegados da África à América; esta memória contém sábios conselhos sobre a maneira de tratá-los durante a travessia, e sobre os meios profiláticos convenientes à maior parte das doenças; além disso, o autor descreve a sarna pustulosa [gale pustuleuse], a disenteria e o escorbuto, que fazem verdadeiras devastações nos carregamentos de escravos, em geral compostos de jovens.

A introdução de negros vindos das costas de Cabinda, de Angola, de Benguela e da parte oriental da África disseminou, nas praias do Brasil, o escorbuto, a sarna, a oftalmia, a varíola [petite-vérole], o piã [pian] e a disenteria; aí estão os inevitáveis acompanhantes do tráfico que estabeleceu entre os dois continentes a troca de doenças mortíferas. Por sua vez, os negros, ao chegar, submetidos a um novo modo de alimentação, à influência de um clima estranho, descuidados das regras de higiene, condenados a trabalhos múltiplos e excessivos, submeteram-se a grandes alterações em sua constituição física, e disto se

* Edição dos trechos de von Martius e de Sigaud, bem como a tradução para o português deste último autor, feitas por Ana Maria G. R. Oda. O texto de von Martius é o traduzido por Pirajá da Silva em 1939, com a grafia atualizada.

7. Memória sobre as doenças agudas e crônicas que mais freqüentemente acometem os pretos recém-tirados d'África. (Nota de Sigaud).

Nota da editora: o nome do autor é Luis Antonio de Oliveira Mendes, mais adiante referido corretamente por Sigaud. A publicação mencionada se chamava Memórias Econômicas da Academia Real das Ciências de Lisboa.

Rev. Latinoam. Psicopat. Fund., São Paulo, v. 11, n. 4, p. 762-778, dezembro 2008 (Suplemento) 
geraram os elementos de doenças que lhes são particulares, verdadeiros atributos da raça negra, tal como a lepra leonina, o mal do estômago [mal d'estomac] e as lesões do sistema cérebro-espinal.

Desportes, Dazille, Bajon e, recentemente, Levacher, que escreveram sobre as doenças da raça negra transportada a Bourbon, a Caiena e às Antilhas, falaram de febres e de inflamações que atacam os negros nestas latitudes tropicais; Lind tratou do escorbuto e da disenteria que entre eles reina; estas descrições podem também se aplicar à raça indígena ou à raça branca, nada havendo de distintivo ou de original que se deva reproduzir. A terapêutica, em compensação, deve sofrer modificações, pois a constituição física e moral do negro difere muito daquela das duas outras raças citadas, exigindo em geral uma medicação mais ativa, sobretudo nos casos de alteração das funções da perspiração, ou da ação solar sobre o sistema cérebro-espinal.

p. 128 e p. 129 :

\section{Doenças nervosas}

Tais doenças têm uma fisionomia especial, e suas evoluções são mais marcadas entre os negros do que entre os brancos. As afecções da medula espinal são muito freqüentes entre os negros, assim como aquelas do cérebro e suas membranas. Alguns autores, Thévenot entre eles, ${ }^{8}$ pretenderam que a inflamação das membranas do cérebro, a loucura e a hipocondria seriam raras entre os negros. Estou longe de compartilhar esta opinião, em razão de grande número de fatos que recolhi e que apóiam opinião contrária. O sistema cérebro-espinal é a sede da doença, freqüentemente, em casos de tétanos, de trismos e de convulsões, que os negros manifestam logo depois de uma grande supressão de suores, de uma comoção violeta, de uma picada [de inseto], de feridas na planta dos pés ou de excessos alcoólicos. A epilepsia, freqüente entre os negros, tem sua fonte em lesão do mesmo sistema; a cólica nervosa, que freqüentemente os mata, talvez nada mais seja do que uma alteração de parte do grande simpático, como o vislumbrou o doutor Segond de Caiena; o mal do estômago [mal d'estomac] é uma nevralgia ligada à mesma ordem de lesões. A afecção tetânica dos recém-nascidos, ou mal de sete dias como é chamada no Brasil, também depende de lesão da medula espinal. O exame de cada uma destas doenças pertence à patologia tropical, e se acha na terceira parte desta obra. Os que defenderam a hipótese de que a loucura era rara entre os negros disseram que somente o idiotismo lhes cabia;

8. Traité des maladies du Sénégal, p. 253. (Nota de Sigaud).

Rev. Latinoam. Psicopat. Fund., São Paulo, v. 11, n. 4, p. 762-778, dezembro 2008 (Suplemento) 
entretanto, os registros dos hospitais da Misericórdia do Rio de Janeiro e da Bahia, onde são trancados os loucos furiosos, dão provas do contrário. O suicídio é muito comum entre os negros das nações Mina e Congo: se entre os primeiros ele é obra de forte resolução, já entre os últimos resulta de completo desarranjo das faculdades mentais, caracterizado por uma mania aguda. O excesso de libertinagem, o abuso da aguardente de cana, a masturbação, o verme chamado de solitária [ver solitaire] provocam convulsões que cedo tomam a forma epiléptica; e se, a princípio, os centros nervosos não são alterados, depois ali se desenvolve progressivamente a lesão.

\section{p. 136 e p. 137 :}

\section{Mortalidade e venenos}

A mortalidade dos negros foi sempre muito grande, em todas as épocas. Não existe documento oficial que permita constatar o número positivo, seja nas paróquias das grandes cidades, seja nos registros das municipalidades. A única declaração que se pode aproveitar é a dos capitães dos navios negreiros, por ocasião de entrar nos portos do Brasil; mas essa declaração registra o número de mortes durante a travessia, e nada oferece para explicar a influência das doenças que os escravos contraem no Brasil, e às quais sucumbem. Por vezes, obtêm-se informações inexatas nessas declarações, pois os capitães muitas vezes tiveram necessidade de esconder o número de mortes ou de o aumentar, de acordo com os interesses do momento. Eu disse que a mortalidade é muito grande; li numa história do Brasil que, dos 1.552 negros que entraram no hospital da Misericórdia em 1792, setecentos e seis (706) sucumbiram.

Aqueles que, como eu, viram o amontoado de cadáveres nos últimos anos do tráfico, em 1830 e 1832, provenientes dos depósitos de negros do bairro do Valongo, compreenderão facilmente que quase a metade deles tenha sucumbido, desse número de 1.552. (...)

$$
\text { p. } 139 \text {, p. } 140 \text {, p. } 141 \text { e p. } 142 \text { : }
$$

Os negros matam ou se suicidam usando venenos vegetais, mas não são os venenos dos índios que os negros conhecem, pois não vivem como eles nas florestas e em contato com a natureza; a maioria deles está encerrada nos ateliês, nas fábricas, ou apartados em turmas, sob vigilância de um comandante, nos trabalhos dos campos ou das minas; se eles têm plantas à sua disposição, são sempre as velhas negras, espécies de feiticeiras, que lhas dão, contando-lhes sobre seus maravilhosos efeitos e ensinando-lhes a maneira de as usar. Entregues a si mes- 
mos, para satisfazer sua vingança ou seu ódio justo ou injusto, eles compram nas cidades e vilas, de comerciantes de ferro e drogas, ${ }^{9}$ o sublimado e o arsênico, sob pretexto de matar ratos, formigas ou os vermes roedore ${ }^{10}$ de madeira e de roupas, substâncias que lhes são entregues sem dificuldade, e das quais fazem uso com a mesma astúcia e a mesma perversidade de que se servem os criminosos de outros países, para os mesmos fins. As plantas que as feiticeiras lhes fornecem são a cicuta, a erva-moura [morelle] ou o estramônio, plantas muito disseminadas nos terrenos vizinhos a todas as cidades ou vilas. Nas cidades, o emprego do vidro moído é geralmente conhecido por aqueles que premeditam um homicídio, e alguns poucos se servem do sumo venenoso da mandioca. Quanto ao suicídio, os negros preferem a forca ao emprego de venenos; todavia, eu vi negros sucumbirem voluntariamente pela mastigação e ingestão de folhas de tabaco.

(...) Vários dos meus colegas quiseram verificar casos reputados como sendo de envenenamento por substância vegetal, de que negros eram acusados, e tal verificação somente produziu a mesma conviç̧ão que eu adquiri em casos idênticos, a saber, que os negros matam com armas e não com venenos; e que, se empregam venenos, dão preferência aos que são de efeito certo, do qual ouviram falar por seus senhores, e que eles podem comprar barato, como o sublimado e o arsênico; enfim, que nos casos de preferência pelos [venenos] vegetais, são os sumos de plantas narcóticas que eles dão, misturados aos alimentos, para amansar [radoucir] seus senhores, segundo sua própria expressão, sumos que se tornam funestos por causarem repetidas perturbações das funções digestivas, mas cuja ação toxicológica se pode facilmente confundir com diversas doenças.

O suicídio é comum entre os negros das raças Mina e Congo; o enforcamento e a sufocação [etouffement] são os meios extremos preferidos ao ferro ${ }^{11}$ e ao veneno. Os escravos entre os romanos conheciam, segundo os relatos de Galeno $^{12}$ e de Valério Máximo, ${ }^{13}$ este modo de terminação, a sufocação. "Um escravo bárbaro - diz Galeno - movido por grande cólera, resolveu se dar a morte: estendeu-se por terra, reteve a respiração e ficou longo tempo imóvel; depois, após algumas agitações convulsivas, ele morreu.” Esta prática consistia em levantar fortemente a língua para trás, fechando assim a laringe por compressão da epiglote, desta forma produzindo sufocação em poucos instantes.

9. As lojas de ferragens, de instrumentos agrícolas, também vendem chumbo, vitríolo, sublimado corrosivo, arsênico, salsaparrilha etc. (Nota de Sigaud).

10. Cupim. (Nota de Sigaud).

11. Nota da editora: ferro no sentido de instrumento cortante, ou arma branca.

12. Galienus, lib. II, ch. VI, edit. 1538, in-fol. (Nota de Sigaud).

13. Valerius Maximus, lib. IX, ch. XII. (Nota de Sigaud).

Rev. Latinoam. Psicopat. Fund., São Paulo, v. 11, n. 4, p. 762-778, dezembro 2008 (Suplemento) 
Apesar de vários fisiologistas negarem a possibilidade deste gênero de suicídio, afirmando que quando se perde a consciência a respiração volta a ser livre, eu creio firmemente nesta prática mortal, pois tive a oportunidade de observá-la três vezes em negros da raça Mina. Grande número de casos semelhantes foi citado por médicos do país, e por cirurgiões que acompanharam os navios negreiros das costas d'África ao Brasil. Lê-se, numa viagem a Angola e ao Congo do padre Zuchelli que, retornando ao Brasil num navio carregado com mais de 700 escravos, o amontoamento causou a morte de 70 negros durante a travessia; exalava do navio um odor insuportável; alguns daqueles infelizes escravos, para se libertarem de seus sofrimentos e para não serem transportados à América, diz o padre missionário, sufocaram-se engolindo sua língua, e caíram logo mortos.

O ciúme, os castigos injustos, a nostalgia, levam freqüentemente os negros a se deixarem morrer, resolução que nada pode vencer, que não cede a ameaça alguma, nem a qualquer espécie de promessa de bem-estar futuro, inabalável até a completa execução do suicídio voluntário. Raymond (sic) Jalama, octogenário que durante dez anos exercera a função de administrador das Companhias de comércio de escravos do Pará e Pernambuco em São Paulo de Luanda, no reino de Angola, e pelas mãos do qual mais de um milhão de negros e negras haviam sido comprados e vendidos, assinalou muitos casos de suicídio provenientes das causas mencionadas; foi citado, entre outros, um depoimento seu sobre fato curioso e interessante, na memória de Luis Antonio de Oliveira Mendes, ${ }^{14}$ que no Brasil teve ocasião de observar mortes lentas, espécies de consumpções produzidas pela inanição, e devidas a uma causa moral. A tendência às idéias funestas é muito comum entre estes infelizes: já os jesuítas recorriam à música para os distrair desta tendência funesta. Os grandes proprietários de engenhos de açúcar, os que dirigem as turmas ${ }^{15}$ de escravos [ateliers], enfim, os plantadores [planteurs] que contam com grande número de escravos imitaram este exemplo, que eles fortalecem o mais que podem com práticas da nossa santa religião.

14. Da enfermidade dos pretos chamada Banzo. (Nota de Sigaud).

Nota da editora: veja-se Oliveira Mendes, 2007 (referência bibliográfica na nota número 4).

15. Nota da editora: atelier poderia ser traduzido por escravaria ou turma, no sentido de um conjunto de escravos dedicados a tarefas específicas nas grandes propriedades agrícolas. Segundo Rafael Marquese, atelier corresponde ao inglês gang; gang system denomina a forma de organização da divisão do trabalho escravo nas plantations (Marquese, Rafael de Bivar. Feitores do corpo, missionários da mente: senhores, letrados e o controle dos escravos nas Américas (1660-1860). São Paulo: Companhia das Letras, 2004. p. 144 e 148).

Rev. Latinoam. Psicopat. Fund., São Paulo, v. 11, n. 4, p. 762-778, dezembro 2008 (Suplemento) 
Terceira seção. Patologia intertropical.

Capítulo VI - Doenças nervosas (p. 357).

\section{Hipocondria, loucura}

Em uma terra agitada por paixões políticas, onde revoluções recentes tumultuaram a sociedade, em um país em que as hemorróidas e a hepatite são reputadas endêmicas, a hipocondria e a loucura certamente são encontráveis, todavia sem que o clima lhes empreste uma nova face. A alienação mental ataca mais os europeus, por causa das suas paixões frustradas, a maioria deles crendo que, só pela força de suas atividades, poderia obter os favores da fortuna em pouco tempo, e para tal tentando o impossível, em detrimento da sua saúde. A mania se observa igualmente entre os negros e se apresenta neles, assim como nos brancos, nas formas conhecidas de melancolia, delírio agudo, monomania, loucura religiosa etc. Os que pretenderam que índios e negros não eram suscetíveis à loucura, na verdade queriam separar estas duas raças das inevitáveis condições da humanidade. Do fato deles serem deixados livres, circulando à vontade nas cidades e nas habitações, da mesma forma que muitos maníacos brancos, e de que só são encarcerados em caso de acessos furiosos, não decorre que índios e negros não apresentem outros estados de loucura além do idiotismo.

Von MarTius

Carl Friedrich Philipp von Martius. Natureza, doenças, medicina e remédios dos índios brasileiros (1844). Tradução, prefácio e notas de Pirajá da Silva. São Paulo: Companhia Editora Nacional, 1939. [Tradução de Das Naturell, die Krankheiten, das Arztthum und die Heilmittel der Uberwohner Brasiliens].

Inércia das funções vitais (p. 28-32)

Tudo quanto até aqui temos dito a respeito das particularidades somáticas dos brasis nos leva a concluir que ocorrem neles deficiência de sensibilidade e retardamento das funções vitais.

Uma observação mais minuciosa demonstra isto. Comparativamente, a força assimiladora dos brasis é muito menor. É fácil a digestão das comidas que lhes são usuais, embora se componham de raízes e frutos verdes, ou de carnes mal preparadas; o mesmo, porém, não acontece com alimentos não habituais e adubados. 
(...) Eles só apreciam o sabor das coisas que lhes são conhecidas e que, por assim dizer, já se identificaram com sua natureza, e conseguem com este modo de viver, sempre metódico, conservar suas forças.

Fora destas condições de vida, os brasis mostram-se logo incomodados e aborrecidos por tudo que os afete de modo contrário à sua vida anterior; em breve definham, em conseqüência de profunda melancolia e desespero em que se acham; perdem o apetite e a agilidade dos membros; caem num abatimento geral e, quase sempre, acabam vítimas de diarréias coliquativas.

Os colonizadores e fazendeiros que empregam os índios como criados ou escravos nos trabalhos de suas fazendas, trazidos por expedições belicosas ou pacíficas, os chamados descimentos, podem muito bem dar testemunho desta grande prostração, desta carência de energias das funções nutritivas, principalmente, nos lugares onde faltam ao índio os encantos da alma e em que se vê sujeito a um modo de viver, de todo contrário ao que levava anteriormente.

Poucas semanas bastam para reduzir o índio mais robusto a um esqueleto, levando-o fatalmente à morte, se não voltar pela própria vontade, pelo auxílio dos companheiros ou, raras vezes também, pelos cuidados humanitários do patrão, à sua primitiva liberdade nas matas.

Essa rápida decadência da nutrição sempre se realiza sob a influência de profunda melancolia e isto com razão é mencionado como prova do grande domínio que têm as influências psíquicas sobre o índio.

Julgamos poder atribuir como causa disto a debilidade do seu sistema plástico. O que dizemos torna-se ainda mais evidente, quando comparamos os brasis com os negros, em idênticas circunstâncias, isto é, sob a influência do sofrimento denominado Banzo, tão conhecido dos possuidores de escravos. Essa nostalgia manifesta-se também nos negros, por um profundo abatimento que na maioria dos casos acaba com a morte. Enquanto o índio quase não exterioriza o que se passa no seu íntimo, e trabalha, se bem que sempre só, embora mandado, parecendo ter-se tornado um autômato que não tem outra idéia senão talvez fugir, no banzo do negro se reflete uma excitação extraordinária de todas as sensações que se acham em relação com seu estado de espírito.

Este desgraçado se entrega então, inteiramente, e com prazer, a suas tristes idéias; a lembrança do passado, que a cada instante se lhe apresenta revestida das mais vivas cores pela exaltação da imaginação, o extasia; abstém-se de todo e qualquer alimento, e parece querer, com estas torturas, dar mais realce ao seu lento e horrendo suicídio. Apesar disto, porém, o negro resiste mais do que o índio aos estragos produzidos por esses sentimentos dolorosos; arrasta, por muitos meses, lânguida existência, até que, por fim, uma repentina hidropisia ou tuberculose galopante o arrebata à vida torturada, que ele parece sentir mais do que o aborígine da América. 
Muitos outros fatores concorrem para o enfraquecimento da nutrição e debilitação dos índios, como por exemplo: a lenta cicatrização das feridas e úlceras, especialmente as dos pés, muitas vezes crônicas, de que são portadores, sem manifesta repercussão sobre o estado geral.

\section{Joseph François Xavier Sigaud (1796-1856)}

Médico francês naturalizado brasileiro, viveu no Brasil entre 1825 e 1856 . Foi médico do imperador Pedro II, editor de periódicos, fundador da Sociedade de Medicina do Rio de Janeiro, membro do Instituto Histórico e Geográfico Brasileiro e atuante filantropo. O seu tratado Du climat et des maladies du Brésil (Do clima e das doenças do Brasil, 1844) é uma importante obra de medicina tropical do século XIX.

\section{Carl Friedrich Philipp von Martius (1794-1868)}

Naturalista (botânico) e médico bávaro que veio ao Brasil na comitiva da arquiduquesa Leopoldina, futura esposa do imperador Pedro I. Em sua expedição científica, viajou pelo país entre 1817 e 1820. Sua obra é vasta, em especial na área de botânica e de etnografia. Seus estudos mais conhecidos são: Viagem pelo Brasil (com von Spix), Flora brasiliensis, e a monografia premiada pelo Instituto Histórico e Geográfico Brasileiro, intitulada Como se deve escrever a história do Brasil. 